\title{
Transportation and Air Pollution in Calabar Metropolis, Cross River State, Nigeria
}

\author{
Egbonyi ${ }^{1}$, Etuki Eborty $\quad$ Omoogun $^{1}$, Remi M. $\quad$ Ivi $^{2}$, Elijah Eghong \\ 1.Department of Environmental Education,University of Calabar,Calabar, Nigeria \\ 2.College of Health Technology, Calabar, Cross River State. Nigeria
}

\begin{abstract}
This study analyzed transportation and air pollution in Calabar metropolis, Cross River State, Nigeria. Two research questions were formulated to examine the contribution of vehicle status and maintenance to air pollution in Calabar metropolis. The ex-post facto research design was adopted. The study population was the number of registered vehicle owners in 2018 which was put at 1,860. While the study sample was 186 which represents $10 \%$ of the total population. A questionnaire was used to collect data from respondents about their vehicle status and maintenance culture and their contributions to the production of air pollutants. Data collected was analyzed using mean rating with a mean cut off point of 2.5 for positive responses. The finding revealed a polled mean of 2.56 for the first cluster which indicated a low status of vehicle for transportation and a pooled mean of 2.74 for the second cluster which indicated poor vehicle maintenance culture. It was therefore concluded that transporters in Calabar metropolis have low status of vehicle and poor vehicle maintenance culture and these contribute to emission of air pollutants in Calabar metropolis. It was therefore recommended that good standard (status) of vehicles should be used for transportation. Transporters in Calabar metropolis should be advised by relevant authorities to practice good vehicle maintenance culture in order to reduce the emission of air pollutants that contributes to air pollution.
\end{abstract}

Keywords: Transportation, Air Pollution, Vehicle Status, and Vehicle Maintenance Culture

DOI: $10.7176 / \mathrm{JETP} / 9-6-03$

Publication date: August $31^{\text {st }} 2019$

\section{Introduction}

Transportation involves the movement of people and goods from one place to another. There are different kinds of transportation. These include land, water and air transport. The commonest transport system used in Calabar metropolis is the land transportation.

Following the ban on motorbikes from the transport system in Calabar metropolis, the only source of vehicular transport (movement) has been cars, buses and tricycles. Automobiles generally contributes to air pollution because the internal combustion engine in motor vehicles burns hydrocarbons fuel to generate motion power, during this process, varying amount of unwanted carbon mono-oxide, hydrocarbons and nitrogen compounds are emitted. Some petrol used by these vehicles contains additive like lead tetraethyl, which pollutes the environment, especially the air. Air pollution according to Anijah-Obi (2001) can be referred to as the contamination of the air we breathe in and occur when the natural state of the atmosphere is being altered by natural or manmade sources, especially when man injects contaminants into the air that may turn the odourless air into hazy smelling air. Abam (2004) stated that air pollution is essentially a product of domestic, social and occupational activities.

Air pollution simply occurs when the atmospheric air becomes impure as a result of pollutants from natural or anthropogenic sources. The anthropogenic air pollutants are more severe than the natural air pollutants. According to United States Environmental Protection Agency (2017) air pollution emitted from transportation contributes to smog, and to poor air quality, which in turn has negative impacts on the health and welfare of the populace. Essentially, pollutants that contribute to poor air quality include particulate matter (PM), nitrogen oxides $\left(\mathrm{NO}_{\mathrm{x}}\right)$, and volatile organic compounds (VOCs) (EPA, 2017). Several epidemiological studies conducted in North America, Latin America, Europe, and some part of Asia have reported associations between trafficrelated air pollution (TRAP) exposure and new-onset asthma in children. TRAP is associated with oxidative injury to the airways, leading to inflammation and remodelling that, in a genetically predisposed individual, could result in asthma development. (Anderson, H.R; Favarato, G. \& Atkinson, R.W. (2013); Bowatte, G; Lodge, C. \& Lowe, A. J; et al. (2014); Khreis, H; Kelly, C; Tate, J; Parslow, R; Lucas, K; Nieuwenhuijsen, M. (2017); Guarnieri, M. \& Balmes, J.R. 2014).

Botkin and Keller (2012) stated that, the two major categories of air pollution sources are stationary and mobile sources, that the stationary sources have a relatively fixed location and include point, fugitive and area sources while the mobile sources of air pollution include automobile, trucks, buses, aircraft, ships, trains and anything else that pollutes as it moves from place to place. Apart from the stationary and mobile sources, air pollutants are also classified as primary and secondary pollutants. The primary pollutants according to Botkin and Keller (2012) are emitted directly in to the air. They include particulates, sulfur dioxide, carbon monoxide, 
nitrogen oxides and hydrocarbons, while the secondary pollutants are produced by reactions between primary pollutants and normal atmospheric compounds example ozone forms over urban areas and through reactions of primary pollutants, sunlight and natural atmospheric gases. Road transport accounted for an estimated 60 percent of PM0.1 (particles smaller than 0.1 microns, also called ultrafines) (Airborne Particles Expert Group, 1999). Agence [2019] reported that, in a wide-ranging study, "researchers examined the emissions from diesel and nondiesel cars, trucks, buses, the shipping industry as well as agricultural and construction machinery and their impact on our health. They found that the global transportation sector was responsible for 11 per cent of the 3.4 million premature deaths annually attributed to pollution from fine particles (PM2.5) and ground-level ozone exposure".

Botkin and Keller (2012) also explain that major air pollutants occur either as particulate matter (PM) or in gaseous forms. Particulates are very small particles of solid and liquid substances and may be organic or inorganic while gaseous pollutants include sulfur dioxide $\left(\mathrm{S}_{02}\right)$ Nitrogen oxide $\left(\mathrm{N}_{02}\right)$ carbon monoxide $\left(\mathrm{C}_{0}\right)$ ozone $\left(\mathrm{O}_{3}\right)$ and volatile organic compounds (VOCs) such as hydrocarbons (compounds containing only carbon and hydrogen that include petroleum products), hydrogen sulfide $\left(\mathrm{H}_{2} \mathrm{~S}\right)$ and hydrogen fluoride (HF). The primary pollutants that account for nearly all air pollution problems according to Botkin and Keller (2012) are carbon monoxide (58\%), volatile organic compounds (11\%), nitrogen oxides (15\%), sulfur oxides $(13 \%)$, and particulates (3\%). According to Linda (2012) Pollutants from cars contribute to various types of air pollution. When hydrocarbons and $\mathrm{NO}_{\mathrm{x}}$ combine in sunlight, they produce ozone. High in the atmosphere, ozone protects us from the sun's ultraviolet rays. When holes in the atmosphere's ozone layer allow ozone to come closer to Earth, it contributes to smog and causes respiratory problems.

Apart from the anthropogenic sources of air pollutants there are also pollutants that occur naturally example sulfur dioxide from volcanic eruptions, hydrogen sulfide from geysers and hot springs, biological delay in bogs and marshes etc. although, natural emissions of air pollutants exceed the anthropogenically produced emissions (except sulfur and nitrogen oxides). It is the human component that is most abundant in urban areas and leads to the most severe problems for human health (Botkin \& Keller, 2012). Transportation is an anthropogenic activity, which accounts for a reasonable percentage of pollutants in the urban areas, especially through automobile exhaust.

More so, according to Jhingan and Chandar (2008) air pollution is caused both by economic development and poverty. That increasing traffic and industrial growth are responsible for the very high level of outdoor pollution in cities. Considering the contribution of economic development and poverty to air pollution, there may be a positive correlation between poverty and air pollution and between economic development and air pollution. Calabar metropolis is in Cross River State, Nigeria. Nigeria is a developing country with a high rate of poverty. Hence, Adesola (2019) opined that Nigeria will retain high poverty rate in 2019 because Nigeria is currently known as the poverty capital of the world. Those living on less than $\$ 1.90$ a day. This is in line with Yomi (2018) report that, the world poverty clock shows that Nigeria has overtaken India. Emphasizing that 86.9 million Nigerians are living in extreme poverty which represents nearly $50 \%$ of its estimated 180 million population and concluded that Nigeria has the highest rate of extreme poverty globally.

This may account for why all the vehicles used for commercial taxi in Calabar metropolis are used vehicles (second, third or fourth hand vehicles). The old vehicles are less costly compare to new vehicles. In Calabar metropolis one hardly sees new vehicles being used for commercial purpose, the popular taxis are old vehicles.

The United States Environmental Protection Agency states that road transport makes up over a quarter of their country's greenhouse gas emissions. While the Society of Motor Manufacturers and Traders (SMMT) in 2017 reported that the average new car emits $120.1 \mathrm{~g} / \mathrm{km}$ of $\mathrm{Co}_{2}$, that the average car currently in use on the road in 2015 emitted $153.9 \mathrm{~g} / \mathrm{km}$ whereas a new car emits only $121.4 \mathrm{~g} / \mathrm{km}$. according to the report, Alternatively Fuelled Vehicle (AFV) such as hybrid cars, emit around 40\% less $\mathrm{Co}_{2}$ and that a diesel car emits $20 \%$ less than a petrol car.

In Calabar metropolis, most of the vehicles used for commercial taxies are obsolete vehicles and are mostly petrol cars, this suggest a high level of co 2 emission and consequently a high level of air pollution even though the pollutant level may be low to produce visible symptoms. More so, Cunningham and Cunningham (2008) revealed that pollutant levels too low to produce visible symptoms of damage may still have important effects. With increase in motorized transport, urban air pollution from road transport is a growing concern in many developing country cities including Nigeria. With rise in urbanization and rising income, the use of cars transport is expected to continue to increase with the potential of worsening air quality. Poor air quality has been shown to have adverse effects on people's health. With the absence of efficient rail mass transit cars will continue to play an important role in public transport in developing countries. The contribution of the transport sector to total CO2 emissions in OECD countries is forecast to increase from approximately 20 percent in 1997 to 30 percent in 2020 (Environment Directorate Environment Policy Committee 2002). In developing countries, with rising income and the rapidly rising mobilization that it triggers, the increase in $\mathrm{CO} 2$ emissions in the coming years will be even greater (Gwilliam, Kojima, \& Johnson, 2004). The World Health Organization (2002) estimated 
that millions of people may died prematurely from urban air pollution. With the absence of efficient rail mass transit cars will continue to play an important role in public transport in most developing countries.

Air pollution affects many aspects of our environment including its visual qualities, vegetation, animals, soils, water quality, natural and artificial structures, and human health (Botkin \& Keller, 2012). According to Abam (2004) automobile exhaust emits carbon, carbon monoxide, carbon dioxide, oxides of nitrogen; formaldehyde and hydrocarbon while fuel or petroleum additives include lead, beryllium, baron and manganese. These pollutants cause lead poisoning, respiratory disorders, toxicity, blood poisoning, irritation to eyes, and skin and other carcino-genic effects.

Cunningham and Cunningham (2008) stated that, the consequences of breathing dirty or polluted air include increased probability of heart attacks, respiratory diseases and lung cancer. This according to Cunningham and Cunningham (2008) can mean as much as a five to ten year decrease in life expectancy especially in worst parts of air polluted areas. Smog and haze caused by air pollution reduces visibility as much as 80 percent such that people find it difficult to see clearly especially from distance.

Vegetations are composed of plants and other organisms. Plants can be damaged by air pollution in many ways, example, the sensitive cell membrane of plants can be damaged by air pollutants, because the toxic level of oxidants produces discoloration which destroys plant chlorophyll and causes necrotic spot and eventual death. Pollutants can also act as hormones, disrupting plant metabolism, growth and development. Cunningham and Cunningham (2008) stated further that, ethylene, a volatile organic compound released in automobile exhaust and from petroleum refineries and chemical plants, often injures plants around roads and factories.

Though carbon dioxide is essential to the survival of plants and animals, too much of carbon dioxide according to Sheri (2018) can cause all life on earth to die. An increase in the amount of carbon dioxide creates an overabundance of greenhouse gases that trap additional heat. If carbon dioxide is confined, according to Sheri (2018) it can decrease the amount of oxygen reaching the body. Any increase or decrease to the amount of carbon dioxide reaching the body can lead to kidney failure or coma. But petroleum operated vehicles emit more carbon dioxide than diesel vehicles and are worst when old. These kinds of vehicles are mostly used for transportation in Calabar metropolis.

The deposition of wet acidic solutions or dry acidic particles from the air became widely recognized as a pollution problem only in the last few decades (Cunningham \& Cunningham, 2008). It causes most soil to be acidic and degrades the quality of the soil needed by some plants and some microorganisms for survival. Water contaminated by acid deposition is no longer pure, and not fit for so many usages.

Lead, when emitted into the air through automobile exhaust, spread widely around, reaching high levels in soils and waters along roadways. Sometimes they are taken up by plants through the soil or are deposited directly on plant leaves and therefore enter terrestrial food chains because plants are primary producers of food. When lead is carried by streams and rivers, deposited in quite waters or transported to oceans or lakes, it is taken up by aquatic organisms and therefore joins the aquatic food chains. According to Botkin and Keller (2012) lead is toxic to wildlife and people; it can damage the nervous system, impair learning and reduce intelligent quotient IQ and memory.

Air pollution can destroy buildings and monuments. In cities throughout the world, air pollution is destroying some of the oldest and most glorious buildings and works of art. Smoke and soot coat buildings, paintings and textiles. Acids according to Cunningham and Cunningham (2008) dissolve limestone and marble, destroying features and structures of historic buildings. The Parthenon in Athens, the Taj Mahal in Agra, the Coliseum in Rome, Medieval Cathedrals in Europe and the Washington Monument in Washington DC, are slowly dissolving and flaking away because of acidic fumes in the air. Air pollution and acid precipitation corrode steel in reinforced concrete, weakening buildings, roads and bridges (Cunningham and Cunningham, 2008).

Anijah-Obi (2001) stated that air pollution is a silent killer because it is very harmful to man's health and can even kill plants. According to Anijah-Obi (2001) the pollutants emitted during the course of any air pollution can irritate human lungs and create more problems for people with asthma and bronchitis. Air pollution can impair mental function and aggravate cardiovascular or heart disease. Acute exposure to hydrocarbons causes eye, nose and throat irritation while chronic exposure causes cancer.

Jenny (2018) maintained that particulate matter, hydrocarbons, carbon monoxide and other car pollutants harm human health. Though hydrocarbons react with nitrogen dioxide and sunlight and form ozone which is beneficial in the upper atmosphere, it is harmful at the ground level. This is because ozone inflames lungs, causing chest pains and coughing and making it difficult to breathe. According to mike (2018) one of the biggest environmental impacts on human activities is air quality. That the transportation sector contributes heavily to air pollution because most forms of transportation including cars, planes and ocean vessels uses fossil fuels, which when burned releases carbon dioxide and other greenhouse gases into the environment and are harmful to human health.

Xenia (2017) also stated that air pollution affects our respiratory system increases the probability of 
suffering from asthma, allergies and any other illness related to it, that air pollution could also damage mental health and even provoke mental illness, especially in children. According to Xenia (2017) anxiety, stress, depression and Alzheimers are just some examples of how pollution can affect mental health, but in children, air pollution can affect mental and cognitive health even more since they are more sensitive to poor air quality.

Air pollution also affects human diet, because vegetation are affected by the poor air quality and so are the animals that eat them. Human are therefore affected because they are at the end of food chain. According to Xenia (2017) there are many more potential consequences that vehicles emissions have on human health, such as heart problems and the enhanced chances of having cancer.

\section{Statement of the problem}

While the advanced worlds are phasing out fossil fuel technology in the automobile mobility, Nigeria has a low tolerant to used vehicle imported from the developed countries. Curiously, in Calabar metropolis new vehicles are not often use for transportation. Cars and buses used for transportation around the metropolis and beyond are old vehicles and are mostly petroleum driven. Petroleum operated vehicles emits more carbon dioxide $\left(\mathrm{Co}_{2}\right)$ than diesel vehicles and are worst when old. To compound the problem, most drivers in Calabar metropolis do not often change their vehicle oil and they have very poor vehicle maintenance culture (habit). This obviously implies a high rate of $\mathrm{Co}_{2}$ and other greenhouse gas emission from those vehicles constituting a serious contributing factor to air pollution in the metropolis. It is disturbing and worrisome that the atmospheric condition in Calabar metropolis and its environs is not friendly, especially due to the fact that the air that people breath is contaminated by smoke, chemicals, smells and particles. Most respiratory disorder and diseases are traceable to air pollution. such has bronchitis and other respiratory disorder. However, sources of air pollution abound. For example pollutant from industries, indiscriminate bush burning, transportation etc. which release emission and contaminate the air that causes air pollution. However such industries are not predominant in the study area. Reports of bush burning are not often heard in the metropolis. Transportation, which also contributes to air pollution, is in categories or kinds such as, air, water and land transport but the most prevalent kind of transportation in calabar metropolis is land transport.

This study therefore gives a highlight of the contributions of air pollution and specifically examined how the status and maintenance culture of vehicles used for land transport in calabar metropolis contribute to air pollution.

This research therefore examined the contribution of transportation to air pollution in Calabar metropolis and proffer solutions to control the release of air pollutants.

\section{Research question}

The following questions were therefore formulated to guide the study.

1. How does the status of vehicle contribute to air pollution in Calabar metropolis?

2. How does vehicle maintenance culture contribute to air pollution in Calabar metropolis?

\section{Methodology}

The ex-post facto research design was adopted in this study. This research design was used because the researcher had no intention of manipulating the independent variables of this study. This design also permit the generalization of the finding to the entire population of study using a given small sample size.

The population of the study is the total number of registered commercial vehicles owners in Calabar metropolis which was given as one thousand eight hundred and sixty vehicles $(1,860)$. (Cross River State Motor License Office

4.1 Sampling technique: Using an accidental sampling technique, 186 drivers representing ten percent (10\%) of the total population were issued with a structured questionnaire.

4.2 Instrumentation: A fifteen-item question was structured using the likert scale of Strongly Agreed, Agreed, Disagreed and Strongly Disagreed to elicit responses from the respondents, about the status of their vehicles and their maintenance culture. Data collected from respondents were analyzed using mean rating to answer the two research questions with a mean cut off point of 2.5 for positive responses.

\subsection{Results/findings}

The result and finding of the study are presented according to the research questions. 4.3.1 Research question 1

How does the status of vehicle contribute to air pollution in Calabar metropolis? 
Table 1: Distribution of mean rating scores on the contribution of vehicle status to air pollution cluster A.

\begin{tabular}{|c|c|c|c|c|c|c|c|c|c|}
\hline $\mathbf{S} / \mathbf{N}$ & ITEMS & & $\begin{array}{l}4 \\
\text { SA }\end{array}$ & $\begin{array}{l}3 \\
\mathrm{~A}\end{array}$ & $\begin{array}{l}2 \\
\mathrm{D}\end{array}$ & $\begin{array}{l}1 \\
\mathrm{SD}\end{array}$ & $\begin{array}{l}\text { Total } \\
186\end{array}$ & Mean & Decisim \\
\hline \multirow[t]{2}{*}{1.} & $\begin{array}{l}\text { The vehicle I am using for transport } \\
\text { was bought as new vehicle so it }\end{array}$ & $\mathrm{N}$ & 4 & 10 & 70 & 10 & 186 & 1.5 & Disagree \\
\hline & contribute less to air pollution & NX & 16 & 30 & 140 & 10 & 288 & & \\
\hline \multirow[t]{2}{*}{2.} & $\begin{array}{l}\text { The Vehicle I am suing for transport is } \\
\text { petroleum driven which contributes }\end{array}$ & $\mathrm{N}$ & 90 & 85 & 4 & 7 & 186 & 3.4 & Agree \\
\hline & highly to air pollution & NX & 360 & 255 & 8 & 7 & 630 & & \\
\hline \multirow[t]{2}{*}{3.} & $\begin{array}{l}\text { The vehicle I am using for transport is a } \\
\text { second hand vehicle which contributes }\end{array}$ & $\mathrm{N}$ & 85 & 91 & 5 & 5 & 186 & 3.4 & Agree \\
\hline & highly to air pollution & NX & 340 & 273 & 10 & 5 & 628 & & \\
\hline \multirow[t]{2}{*}{4.} & $\begin{array}{l}\text { I am using a diesel driven vehicle for } \\
\text { transportation which contributes less to }\end{array}$ & $\mathrm{N}$ & 4 & 6 & 90 & 86 & 186 & 1.6 & Disagree \\
\hline & air pollution & NX & 14 & 18 & 180 & 86 & 300 & & \\
\hline \multirow[t]{2}{*}{5.} & $\begin{array}{l}\text { I have been using the same vehicle for } \\
\text { more than a decade hence have }\end{array}$ & $\mathrm{N}$ & 80 & 46 & 30 & 30 & 186 & 2.9 & Agree \\
\hline & contribute highly to air pollution & NX & 320 & 138 & 60 & 30 & 548 & & \\
\hline
\end{tabular}

From the analysis of data presented in table 1, the distribution of scores shows that the status of vehicles in Calabar metropolis contribute to air pollution. The five items taken one by one indicates expected mean of 1.5 , 3.4, 3.4. 1.6 and 2.9 respectively, and a pooled mean of 2.56 greater than the stated mean of 2.5. The findings could be attributed to the low status of vehicles used for transportation.

\subsubsection{Research question2}

How does vehicle maintenance culture contribute to air pollution in Calabar metropolis?

Table 2: Distribution of mean rating scores on the contribution of vehicle maintenance culture to air pollution.

\begin{tabular}{|c|c|c|c|c|c|c|c|c|c|}
\hline $\mathbf{S} / \mathbf{N}$ & ITEMS & & $\begin{array}{l}4 \\
\text { SA }\end{array}$ & $\begin{array}{l}3 \\
\mathrm{~A}\end{array}$ & $\begin{array}{l}2 \\
D\end{array}$ & $\begin{array}{l}1 \\
\text { SD }\end{array}$ & TOTAL & MEAN & Decisim \\
\hline 1. & $\begin{array}{l}\text { I change the engine oil of my vehicle } \\
\text { frequently thereby reducing emission of } \\
\text { pollutants }\end{array}$ & NX & 10 & 16 & 150 & 85 & 186 & 1.7 & Disagree \\
\hline 2. & $\begin{array}{l}\text { I always buy second hand part to replace } \\
\text { damaged parts of my vehicle and this } \\
\text { contribute to high emission of pollutants }\end{array}$ & NX & 328 & 210 & 20 & 14 & 186 & 3.2 & Agree \\
\hline 3. & $\begin{array}{l}\text { I do buy fuel from roadside seller and } \\
\text { this contribute to high emission of air } \\
\text { pollutants }\end{array}$ & $\begin{array}{c}\mathrm{N} \\
\mathrm{NX}\end{array}$ & $\begin{array}{l}80 \\
320\end{array}$ & $\begin{array}{l}64 \\
192\end{array}$ & $\begin{array}{l}20 \\
40\end{array}$ & $\begin{array}{l}22 \\
22\end{array}$ & $\begin{array}{l}186 \\
574\end{array}$ & 3.1 & Agree \\
\hline 4. & $\begin{array}{l}\text { I do buy refill oil to change my vehicle } \\
\text { oil and this contribute to emission of air } \\
\text { pollutant }\end{array}$ & NX & 300 & 234 & 15 & 18 & $\begin{array}{l}186 \\
582\end{array}$ & 3.1 & agree \\
\hline 5. & $\begin{array}{l}\text { I always carry passengers in my vehicle } \\
\text { without regards to approved standard this } \\
\text { contribute to spoilage of vehicle and gas } \\
\text { emission }\end{array}$ & NX & 200 & 144 & 45 & 43 & 186 & 2.6 & \\
\hline
\end{tabular}

From the analysis of data presented in table 2, the distribution of scores shows that, the vehicle maintenance culture of transporters in Calabar metropolis is poor and contributes to the emission of air pollutants. The five items taken one-by-one indicate expected means of 1.7, 3.2, 3.1, 3.1 and 2.6 respectively with a pooled mean of 2.74 greater than the stated mean of 2.5. The finding could be attributed to the poor vehicle maintenance culture of transporters in Calabar metropolis, poverty and ignorance in the part of most taxi drivers.

Result of research question one revealed that transporters in Calabar metropolis have low status of vehicle which contribute to emission of air pollutants. This agrees with Mike (2018) that the transportation sector contributes to air pollution. It is also in harmony with Sheri (2018) that petroleum operated vehicles emit more carbon dioxide than diesel vehicle and are worst when old.

The result of research question two revealed that transporters in Calabar metropolis have poor vehicle maintenance culture which contributes to emission of air pollutants. This is in harmony with the South Carolina Department of Health and Environmental Control (SCHEC) that removal of extra weight from vehicle and making repairs quickly can reduce the vehicle emission and improve air quality.

\section{Conclusion}

The study examined transportation and air pollution in Calabar metropolis. The result of data analysis showed 
that transporters have low statues of vehicles and poor vehicle maintenance and this contributes to the emission of pollutants which causes air pollution. Data analysis shows that the mean scores of the responses were above the stated mean of 2.5. Based on these findings, it was concluded that transportation in Calabar metropolis contributes to air pollution. There is need also for the overall policy for efficiency improvements in the urban transport system through infrastructure investments or land use policy, or through fiscal policies that can affect fuel and vehicle technology choice, fuel consumption, and vehicle use. For example, the developed countries should stop exporting used vehicles to developing countries Urban towns should invest also in alternatives nonvehicular transport through building and protection of pedestrian and bicycle paths, including policies that promote public transport (Gwilliam, Kojima, \& Johnson, 2004) The transition to zero-emission vehicles that will replace internal combustion engines being developed in Europe and elsewhere must be far reaching and the developed economy must carry alone the third world countries. It will be unwise ecologically to ship these combustion engines vehicles to these poor countries. After all, the ozone layer has no boundary

\section{Recommendations}

1. Good standard (status) of vehicle should be used for transportation to reduce the emission of pollution that causes air pollution. Effective interventions for reducing transport-related emissions must target the individual cars and ensure such cars are properly maintained to reduce emission.

2. Transporters especially drivers in Calabar metropolis should be adviced by relevant authorities to practice good vehicle maintenance culture to reduce the emission of pollutants that contribute to air pollution.

3. Vehicles using diesel should be replaced with vehicles using petroleum to reduce the amount of carbon emitted by them. There is also a growing consensus that diesel exhaust poses a serious cancer risk (Lloyd and Cackette 2001)

4. This research is not experimental in nature and did not determine the actual emission of maintained and non-maintained within the study area. Further research should be conducted over a longer period to established rate of emission in the study area.

\section{References}

Abam, O. T. (2004). Environmental Science in Concepts and Principles. Anrison Printers and Publishers, Calabar - Nigeria

Agence France-Presse[ 2019] Environmental Pollution health transportation and mobility March 8.

Airborne Particles Expert Group. 1999. "Source Apportionment of Airborne Particulate Matter in the United Kingdom.” January. www.defra.gov.uk/environment/airquality/airbornepm/.

Anderson, H.R; Favarato, G. \& Atkinson, R.W. (2013). Long-term exposure to air pollution and the incidence of asthma: meta-analysis of cohort studies. Air Qual Atmos Heal. 6: 47-56

Anijah-Obi, F. N. (2001). Fundamentals of Environmental Education and Management. University of Calabar Press. Calabar - Nigeria

Botkin, D. R. \& Keller, E. A. (2012). Environmental Science. International Student Version, Wiley

Bowatte, G; Lodge, C. \& Lowe, A. J; et al. (2014).The influence of childhood traffic-related air pollution exposure on asthma, allergy and sensitization: a systematic review and a meta-analysis of birth cohort studies. Allergy. 70: 245-256

Cunningham, W. P \& Cunningham, M. A. (2008). Principles of Environmental Science, Inquiry and Application. Higher Education, New York.

Global Refining \& Fuels Report. . (2003). “'No Diesel Without Filter' Campaign Seen Winning Battles with Automakers." May 14.

Guarnieri, M. \& Balmes, J.R. (2014). Outdoor air pollution and asthma. Lancet. 383: 1581-1592

Gwilliam, K; Kojima, M. \& Johnson, T 2004]. Reducing Air Pollution from Urban Transport. Washington, D.C:The International Bank for Reconstruction and Development/THE WORLD BANK 1818 H Street, N.W.

Jenny, G. (2018). Effects of Car Pollutants on the Environment, Sciencing, http://sciencing.com>

Jhingan, M. L. \& Sharima, C. K. 92008). Environment Economics, Theory, Management and Policy, $2^{\text {nd }}$ Edition. Vrinda Publications (p) Ltd. Delhi

Linda C. Brinson(2012). "How much air pollution comes from cars?" 29 August .HowStuffWorks.com. $<$ https://auto.howstuffworks.com/air-pollution-from-cars.

Khreis, H; Kelly, C; Tate, J; Parslow, R; Lucas, K; Nieuwenhuijsen, M. (2017) Exposure to traffic-related air pollution and risk of development of childhood asthma: a systematic review and meta-analysis.Environ Int. 100: $1-31$

Lloyd, Alan C., and Thomas A. Cackette. 2001. "Diesel Engines: Environmental Impact and Control." Journal of Air and Waste Management Association 51:809-847.

Mike, S. (2018). The Effects of Human Intervention on the Environment. http://scienceing.com 
Sheri, L. (2018). How does Carbon Dioxide affect the Environment. http://scinecing.com

United States Environmental Protection Agency (2017). https://www.epa.gov/air-emissions-inventories/multipollutant-comparison)

World Bank . (2002). "Urban Air Pollution: What Do We Know About Air Pollution?-India Case Study." South Asia Urban Air Quality Management Briefing Note No. 4. Washington,D.C. Available online at: www.worldbank.org/sarurbanair.

Xenia (2017). Air Pollution: The Facts (and the Quickest Way to make a Difference). Lightfoot 